\title{
Why Is Epistemic Evaluation Prescriptive?
}

\author{
Kate Nolfi \\ UNC Chapel Hill \\ (Forthcoming in Inquiry, Special Issue on the Nature of Belief, edited by Susanna Siegel)
}

\begin{abstract}
Epistemic evaluation is often appropriately prescriptive in character because believers are capable of exercising some kind of control - call it doxastic control - over the way in which they regulate their beliefs. An intuitively appealing and widely endorsed account of doxastic control - the immediate causal impact account - maintains that a believer exercises doxastic control when her judgments about how she ought to regulate her beliefs in a particular set of circumstances can cause the believer to actually regulate her beliefs in those circumstances as she judges she ought to. I show here that the immediate causal impact account is ultimately untenable. Nevertheless, the immediate causal impact account gets something important about the nature of doxastic control right: exercising doxastic control involves being such that one's conception of ideal belief regulation somehow shapes the way in which one actually regulates one's beliefs. Thus, I develop here an alternative account according to which, insofar as she exercises doxastic control, a believer's conception of ideal belief regulation shapes the way in which she actually believes by exerting causal power directly on her dispositions to regulate her beliefs in certain ways. I defend this alternative against other competitors by showing that it can be extended to supply a unified account of rational control that explains evaluation with respect to the various different norms of rationality that govern the way in which we form, revise, and sustain not only our beliefs, but also our intention, hopes, fears, etc. is often appropriately prescriptive.
\end{abstract}

\section{Introduction}

If I say that a particular thermostat ought to turn on the heater when the ambient temperature drops below 65 degrees, I am describing a standard of proper functioning that governs the thermostat's operation. But I am not instructing the thermostat to operate in this way, nor am I providing the thermostat with guidance or advice. My statement that the thermostat ought to turn on the heater when the temperature drops below 65 degrees does not tell the thermostat how to respond to the ambient temperature.

The epistemic 'ought,' however, is often used to express guidance or advice regarding how to form, revise, or sustain one's beliefs. Evaluation with respect to epistemic standards - and, in particular, with respect to standards of epistemic rationality or justification - is often naturally interpreted as instructing or directing its target to 
reason in certain ways and not others. Thus, the epistemic 'ought' is often prescriptive, rather than merely evaluative. , $^{1,2}$

Why is the epistemic 'ought' different in this regard from the 'ought' of proper functioning that applies to the operation of a thermostat? ${ }^{3}$ Plausibly, one reason is that it makes no sense to give instructions to someone or something that is thoroughly incapable of adjusting its performance in response to those instructions. And a thermostat's operation can never be responsive to or guided by the instructions, directions, or advice that might be embedded in a claim about how it ought to operate. Advice, guidance, or direction presupposes that its target is (at least in normal circumstances) capable of following or being guided by its recommendations. ${ }^{4}$ This suggests that the fact that a believer is capable of changing the way she regulates her beliefs in response to and in a way that is guided by epistemic praise or criticism explains (at least in part) why she is an appropriate target of prescriptive evaluation for believing as she does. ${ }^{5}$ Put in other terms, it is the fact that a believer can exercise some yet-to-be-specified kind of control over either the content of her beliefs or over the processes that regulate them that explains (at least in part) why she is appropriately subject to epistemic evaluation that is

\footnotetext{
${ }^{1}$ Certainly epistemic evaluation that takes the form of praise or criticism with respect to standards of epistemic rationality or justification marks the fact that a believer has either met or fallen short of these standards in believing as she does. My point here is that this sort of epistemic evaluation is often more than a mere tool for marking whether or not a believer manages to live up to these epistemic standards. Rather, this evaluation is just evaluation that has directive or instructive import. The prescriptive 'ought' supplies advice or guidance. And normative claims that employ the prescriptive 'ought' tell someone or something how to be, how to act, or how to perform. This is what differentiates prescriptive evaluation from evaluation that merely reports whether or not its target conforms to a particular normative standard that governs it.
}

2 The prescriptive/merely evaluative distinction that I draw here cuts across the ought-to-be/ought-to-do distinction to which Chrisman appeals in his (2008). Nothing in what follows turns on whether the kind of genuinely prescriptive epistemic evaluation on which I've focused my attention here - evaluation with respect to standards of rationality or justification - is understood as evaluation with respect to ought-to-bes (rules of criticism) or ought-to-dos (rules of action). Additionally, I remain agnostic regarding how this distinction is properly captured by a theoretical semantics of 'ought' (for a helpful discussion of the debate on this point, see Chrisman (2012)).

${ }^{3}$ This question is especially pressing if, as some epistemologists suggest, epistemic standards or norms have roughly the same kind of normative structure as the standards of proper functioning that govern e.g. thermostat operation, heartbeats, human perception, or animal cognition (see, for example, Sosa (2009) or Kornblith (2002)).

${ }^{4}$ This is why epistemic evaluation that is genuinely prescriptive in character seems confused, misguided, or misplaced when its target is a believer who, perhaps because of some deficiency or defect in her cognitive capacities, is systematically incapable of regulating her beliefs differently from the way in which she does. Of course, such a believer might well be appropriately subject to non-prescriptive epistemic evaluation.

${ }^{5}$ One other part of a complete explanation of when and why believers are appropriately subject to prescriptive epistemic evaluation in virtue of the way in which they believe must be an explanation of why believers fall under the scope of epistemic standards - i.e. of why epistemic norms have authority over the way in which believers believe - in the first place. For the purposes of this paper, I will simply assume that, somehow, epistemic standards do have the requisite sort of authority over the way in which we believe. 
prescriptive, rather than merely evaluative, in character. ${ }^{6}$ Call the relevant kind of control, whatever it turns out to involve, doxastic control. So, doxastic control is that which ensures that a believer is capable of responding to, following, or taking up and putting into practice instructions, directions, or advice regarding how she ought to regulate her beliefs. If a believer lacks the capacity to exercise doxastic control, then she is not appropriately subject to evaluation with respect to standards of epistemic rationality or justification that is genuinely prescriptive in character. And the fact that we typically exercise doxastic control explains why we are typically appropriate targets of prescriptive epistemic evaluation.

Thus, the real work of explaining when and why the epistemic 'ought' is genuinely prescriptive lies in giving an account of doxastic control. The aim of this paper is to develop and defend such an account.

\section{The Simple Account: Control as Immediate Causal Impact}

Perhaps the most intuitive and certainly the most widely endorsed account of doxastic control is what I call here the immediate causal impact account. Put roughly, the immediate causal impact account of doxastic control maintains that we exercise doxastic control if and only if our judgments about how we ought to believe in a particular set of circumstances cause us to actually believe in the ways that we judge we ought to believe in those circumstances. ${ }^{7}$

Of course, proponents of the immediate causal impact account accept that we do not always, or even typically, make judgments about how we ought to believe in the course of actually forming, revising, or maintaining our beliefs. Much of our belief regulation occurs automatically and unreflectively. Still, we are capable of making normative judgments about how we ought to believe in the circumstances with which we are faced. The immediate causal impact account maintains that a believer who exercises doxastic control is just a believer who is such that, when she does make such judgments, her judgments causally determine how she actually believes. As a first gloss, that a believer exercises doxastic control in now believing that $\mathrm{P}$ requires that, if she were to judge that she ought not now believe that $\mathrm{P}$, then her judgment would cause her not to now believe that $\mathrm{P}$. More carefully, that a believer exercises doxastic control in believing as she now does requires that, were the believer to make a certain sort of judgment about how she ought to now believe, her judgment would, itself, causally determine the way in

\footnotetext{
6 The notion of control is closely linked to the notions of freedom, agency, and responsibility. Although I focus exclusively on the notion of control in this paper, I do think that the applicability of the prescriptive 'ought' (both in the epistemic domain and elsewhere) is tied to the applicability of a certain form of responsibility, and presupposes both a certain kind of freedom and the capacity to exercise a certain sort of agency on the part of the evaluative subject. In future work, I hope to employ the particular account of doxastic control that I defend in what follows to explicate both the nature of our doxastic freedom, and the sense in which, as Boyle suggests in his (2011), we exercise a kind of agency in believing.

7 Although I will not mark this explicitly in the text, the normative judgments to which I refer here and below when discussing doxastic control express a believer's own conception of ideal belief-regulation and so these normative judgments always employ the epistemic 'ought.'
} 
which she would actually now believe. And, if the immediate causal impact account is right, then a believer is appropriately subject to prescriptive epistemic evaluation in virtue of how she believes in a particular case only when either the way in which she believes actually is causally determined by her judgment(s) about how she ought to believe in the case in question or the way in which she believes would have been so determined, had she made the relevant sort of judgment.

There are a variety of different ways in which one might understand the mechanism via which certain of a believer's normative judgments about how she ought to now believe causally determine how she actually now believes to which the immediate causal impact account of doxastic control appeals. Some proponents of the immediate causal impact account suggest that a believer exercises doxastic control because her judgments about how she ought to believe in a particular set of circumstances causally determine the content of her belief in those circumstances. On this sort of proposal, a believer's normative judgment about whether it would be rational or justified to now believe a particular proposition $\mathrm{P}$ on the basis of her current perceptual experience, the other beliefs she now has, etc. causes her to have a belief with $\mathrm{P}$ as its content. ${ }^{8}$ There are a number of different ways in which we might model this mechanism. Here are two.

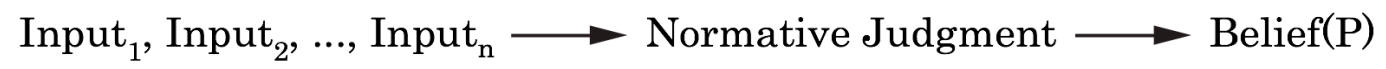

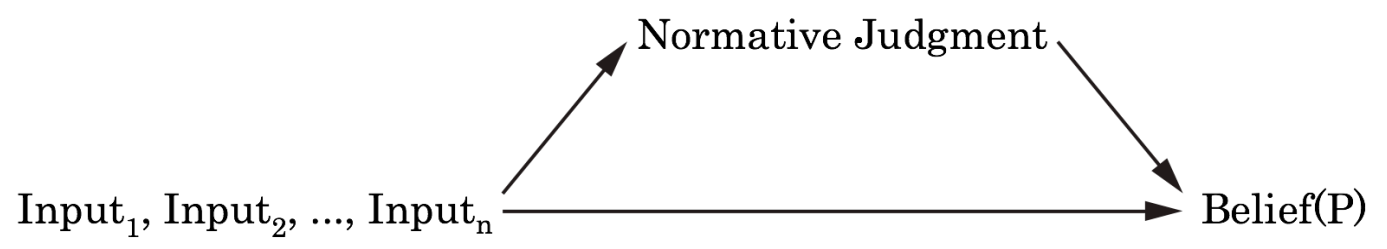

What unifies these models is that, on each, the subject's judgments about whether she ought to now believe that $\mathrm{P}$ exerts causal power directly on her current belief. So, when a believer exercises doxastic control over her beliefs, the fact that she forms a judgment about what content she ought to believe in a particular case is sufficient to cause her to believe that content in that case.

Other proponents of the immediate causal impact account maintain, however, that it is the causal upshot of a believer's normative judgments about how she ought now to regulate her beliefs (and not her judgments about what particular contents her beliefs ought now to have) that determine whether or not a believer exercises doxastic control in

${ }^{8}$ Scanlon (1998) and McDowell (1994) both appear to endorse versions of this account - call it the reflective control account - of the relevant causal mechanism. David Owens also reads Korsgaard as endorsing a version of account, but I think that, in fact, what Korsgaard says in her (1996) does not clearly distinguish between the reflective control account and what I call the constitution account below. In later work Korsgaard more clearly rejects the reflective control account in favor of the constitution account. More recently, Shah (ms.) seems to suggest that he favors the reflective control account, where a second-order reflective state directly causes first-order belief, over the account of this mechanism that I consider next. 
believing. ${ }^{9}$ On this proposal, a believer exercises doxastic control when her judgment that she ought now to believe truly or in a way that conforms with some other, perhaps more narrowly specified, epistemic norms modulates the cognitive processes (i.e. the, perhaps subconscious, reasoning) that now generate and/or sustain her belief. Suppose, for example, a believer judges that she ought not believe that $\mathrm{P}$ in the circumstances with which she is currently faced unless her total evidence makes it probable that $\mathrm{P}$ is true. Assuming this believer exercises doxastic control in the case at hand, her judgment must be causally efficacious in shaping the character of the processing which actually gives rise to and/or sustains a belief about whether $\mathrm{P}$ in the circumstances at hand such that that she only ends up believing that $\mathrm{P}$ (rather than suspending or disbelieving that $\mathrm{P}$ ) if she takes her total evidence to make $\mathrm{P}$ probable. Her judgment must cause it to be the case that only considerations this believer takes to make $\mathrm{P}$ probable will actually give rise to or sustain (by serving as the basis for) her belief that $\mathrm{P}$ in the circumstances at hand.

We can model the this mechanism as follows.

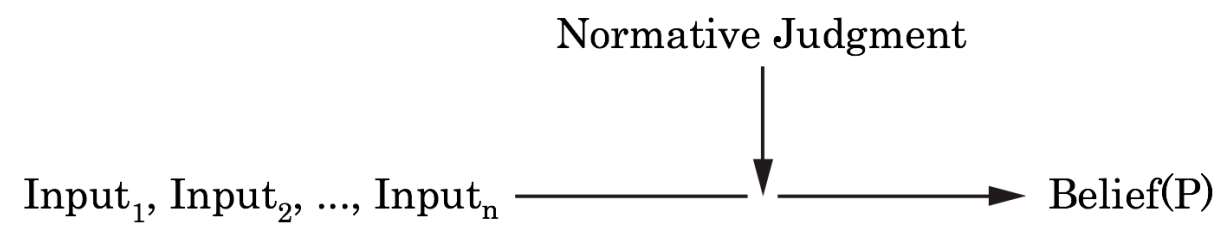

Here, the relevant sort of judgment exerts its causal power directly on the cognitive processing that gives rise to and/or sustains belief in the circumstances at hand and so only indirectly on the content of the resulting belief.

Regardless of which of these mechanisms the proponent of the immediate causal impact account endorses, however, the psychology of a believer who exercises doxastic control in believing that $\mathrm{P}$ in a particular set of circumstances must be such that, were she to have made the relevant sort of normative judgment, this normative judgment would have causally determined how she actually believes in the circumstances at hand. So, on the immediate causal impact account whether a believer exercises doxastic control is fundamentally a matter of whether she is wired up, so to speak, in the right sort of way. We exercise doxastic control in now believing as we do when we are psychologically constituted such that any judgments about how we ought now to believe that we happen to make will be causally efficacious either in shaping the processes that now give rise to and sustain belief or in determining the content of what we now believe. And so, if the immediate causal impact account is right, then we are appropriately subject to prescriptive epistemic evaluation for believing as we do in the particular set of circumstances with which we are now faced because we are capable of immediately causally determining how we believe in the circumstances with which we are now faced by making a judgment about how we ought to believe in those circumstances.

\footnotetext{
${ }^{9}$ In their (2005), Shah and Velleman seem to presuppose that we exercise something like this kind of control over our beliefs. Sosa (forthcoming) also seems to endorse a version of this sort of mechanism as the mechanism of doxastic control.
} 


\section{Why the Immediate Causal Impact Account Fails}

Despite its intuitive appeal, the immediate causal impact account of doxastic control is untenable. And this is because the immediate causal impact account implausibly restricts the scope of prescriptive epistemic evaluation.

In cases where we believe rationally, our judgments regarding how we ought to believe cannot exert their causal power over how we actually believe in the way that the immediate causal impact account of doxastic control describes. ${ }^{10}$ Thus, endorsing the immediate causal impact account commits one to denying that we exercise doxastic control when we believe rationally, and so denying that we are appropriately subject to genuinely prescriptive epistemic evaluation for believing in a great many of the cases in which it seems that we are. But it seems that we are appropriately subject to prescriptive epistemic evaluation for believing as we do in cases where we believe rationally.

It will be easier to bring out precisely why an immediate causal impact account of doxastic control entails that we do not exercise doxastic control when we believe rationally by considering a concrete case. To this end, imagine that I look out of my office window and see that the pavement is wet, that the sky is gray, and that the trees are dripping. I find myself believing, on the basis of my visual experience, that it has rained. ${ }^{11}$ Since I have no reason to think that my visual experience is misleading with respect to the recent weather, my belief is both rational and justified. And I am epistemically praiseworthy for believing as I do. I form my belief about whether it has rained in this case in precisely the way that I (epistemically) ought to form such beliefs on the basis of my visual experiences. Moreover, the kind of praise to which I seem appropriately subject in this case is not merely evaluative. The claim that I ought now to believe in the way that I do does not merely report that I now believe in a way that conforms to epistemic standards, nor does it function exclusively as a kind of sticker of approval. Rather, it would be natural to interpret this positive evaluation as instructing me to continue to sustain my belief in the way that I currently do, as advising me to go on believing that is has rained on the basis of my visual experience just as I do now, and perhaps even as directing me to form beliefs in similar ways in future situations. And, as such, this evaluation is (or, at the very least, it can be) genuinely prescriptive in character. ${ }^{12}$

\footnotetext{
10 The arguments in defense of this conclusion that I offer below are inspired by and loosely track reasoning that David Owens puts forward in Chapter 2 of Owens (2000). A somewhat similar sort of argumentative line (marshaled in support of the claim that following an epistemic rule cannot be understood in terms of the believer having an intentional state representing the relevant rule that explains - causally-and rationalizes the believer's believing in the way that she does) runs through Boghossian (2008).

${ }^{11}$ Nothing in what follows turns on the fact that this case involves perceptual belief. The same points might be made by appeal to a case involving, for example, a simple deductive inference.

12 If I believed that it had not, in fact, rained, but rather that the view through my office window had been carefully manipulated to make it appear as if it had rained-perhaps I believe that the window has been given a gray tint and that the area outside has been sprayed with a fire hose by mischievous students who hope to mislead me regarding today's weather - then, given how unlikely I know this all is, I would be appropriately subject to epistemic criticism. Epistemic norms dictate that, in light of what else I know, I
} 
Since being subject to prescriptive epistemic evaluation entails that one exercises doxastic control, it must be that I exercise doxastic control in believing that it has rained in the case at hand. And if the immediate causal impact account is right, then exercising doxastic control in now believing that it has rained requires that, were I to make a certain sort of judgment about how I ought to believe in the circumstances with which I am faced, my judgment would cause how I actually believe in the circumstances at hand to conform to the way in which I judge that I ought to now believe. However, there is good reason to think that my judgments about how I ought to believe in the circumstances with which I am now faced cannot be causally efficacious in this way. There is good reason to think, that is, that my judgments about how I ought to believe in the circumstances with which I am now faced cannot causally determine either the character of my current reasoning or the content of my current belief. And this is because a closer look at what believing rationally requires reveals that judgments about how one ought to believe in the circumstances with which I am faced cannot play either of these causal roles in generating or sustaining a rational belief. It will be helpful treat the two different mechanisms of immediate causal impact that I discuss above in turn.

On the first proposal, I exercise doxastic control in believing, on the basis of my visual experience as of gray sky, wet pavement, and dripping trees, just in case, were I to judge that I ought to believe that $\mathrm{P}$ in the circumstances with which I am now faced, my judgment would cause me to believe that P. Imagine that, as I have a visual experience as of a gray sky, wet pavement, and dripping trees outside my office window, I judge that I ought now, on the basis of my experience, believe that it has rained. Can it be that my judgment is that which causes me to believe that it has rained in the circumstances at hand? Well, it would, of course, be possible for me to me to believe rationally in the circumstances with which I am now faced, even if I had not made this judgment. Thus, it must be that my visual experience (perhaps along with certain of my background beliefs) is sufficient to serve as the rational basis and so as the causal ground for my belief that it has rained in this case. Whether or not I make the relevant sort of judgment, my visual experience and my background beliefs can do all the causal work that there is to be done in generating and sustaining my belief that it has rained in the circumstances at hand.

Now, certainly there would be something wrong with me, at least epistemically speaking, were I to judge that I ought now believe that it has rained and yet now fail to so believe. But the best explanation for this is not that, if I am to believe rationally in a case where I make the relevant judgment, then my belief that it has rained must be a causal product of my judgment that I ought to now so believe. Rather, it seems that, at least when all goes well, my belief and my judgment share a common causal ground. If my judgment is well-founded, then it seems my normative judgment must itself be grounded

ought not to have taken seriously the possibility that my visual experience as of wet pavement, gray sky, etc. was the result of an elaborate hoax in this way when forming my belief. Moreover, there is no reason to think that the criticism to which I am appropriately subject here should not be genuinely prescriptive in character. My colleagues would be warranted in chiding me for failing to draw a reasonable, rational, or justifiable conclusion about the weather in response to my visual experience, and it is natural to think that their criticism here constitutes advice or guidance to the effect that I should have believed differently in the case at hand. 
on and so be a causal product of the same visual experience (and background beliefs) that ground my belief that it has rained. After all, the reasons that I believe that it has rained in the case at hand must include that my perceptual experience is as of the sky being gray, the pavement being wet, etc. And it is for precisely these same reasons that I would be right to judge that I ought now to believe that it has rained. So, if I believe rationally, then whatever it is on the basis of which I judge that I ought now to believe that it has rained must also be that which explains why I now believe as I do. And if this is right, then there is no reason to think that my judgment figures at all in a causal explanation of why I now believe that it has rained. More generally, in cases where the content of what I now believe conforms to my judgment about what I ought now to believe, whatever it is that grounds my judgment (and not my judgment itself) will do all the causal work that needs to be done in generating or sustaining my belief. We have good reason to expect, then, that a complete causal explanation of the fact that I come to believe as I do in the circumstances at hand need not ever mention my judgment that I ought to so believe. Thus, it would be unparsimonious at best and over-intellectualizing at worst to suppose that my judgment that I ought to believe it has rained is, itself, causally efficacious in the relevant way in bringing it about that I believe that it has rained. Instead, we ought to conclude that my judgment is epiphenomenal - a kind of fifth wheel - with respect to the causal explanation of how it is that I come to believe as I do in the circumstances at hand. And since my judgment cannot be that which causes my belief to have the content that it has, I cannot, on the proposal under consideration here, exercise doxastic control in believing that it has rained in the circumstances at hand.

Let us turn, now, to the second proposal regarding the mechanism of immediate causal impact that underwrites doxastic control introduced above. On this proposal, that I exercise doxastic control in the case at hand requires that, were I to judge that I ought to believe that it has rained only if believing that it has rained constitutes conformity with, e.g., a truth norm or with norms of epistemic rationality in the case at hand, my judgment would causally determine the character of the cognitive processing (i.e. the, perhaps subconscious, reasoning) that gives rise to and sustains my belief that it has rained. So, imagine that, as I look out my office window at the gray sky, wet pavement, and dripping trees, I judge that I ought only believe that it has rained on the basis of my visual experience if my visual experience makes it probable that it has rained. If I exercise doxastic control in the case at hand, it must be that my judgment causes me to regulate my belief in such a way that I only end up believing that it has rained on the basis of my visual experience in the case at hand because my visual experience makes it probable that it has rained. Assume that my judgment is correct: were it not the case the my visual experience made it probable that it has rained, my belief that it has rained in the circumstances at hand would be epistemically irrational. Thus, if I now believe rationally that it has rained on the basis of my visual experience, then it must be that I regulate my belief in such a way that I only end up believing that it has rained on the basis of my visual experience in the case at hand because my visual experience makes it probable that it has rained. And since it would have been possible for me to believe rationally here without having ever made the relevant judgment, there is good reason to think that my judgment is not what causes me to regulate my belief in this way. There must be some 
causal explanation for why it is that I regulate my belief that it has rained in ways that are rational in similar cases where I make no judgments about how I ought to regulate my beliefs in the circumstances with which I am faced. And whatever causal explanation there is will apply equally well to the case at hand where I do make a judgment of the relevant sort. This suggests that my judgment that I ought not now believe that it has rained on the basis of my visual experience unless my visual experience makes it probable that it has rained is not that which causally determines the way in which I regulate my belief in the case at hand. To suppose otherwise would be unparsimonious at best and over-intellectualizing at worst. It seems that my judgment must be a kind of epiphenomenon - a fifth wheel - in any causal account of the character of the cognitive processing (i.e. the reasoning) that gives rise to and sustains my belief that is has rained. And since my judgment cannot be that which causes me to regulate my beliefs in the way that I do, I cannot, on the proposal under consideration here, exercise doxastic control in believing that it has rained in the circumstances at hand.

Regardless of how we describe the particular mechanism of immediate causal impact, the immediate causal impact account of doxastic control sets the bar for exercising doxastic control too high. In cases like the one I have described here, a believer seems to be appropriately subject to genuinely prescriptive evaluation in virtue of how she believes even though the believer's judgments about how she ought now to believe cannot causally determine the character of the belief-regulating processes that give rise to or sustain her belief, nor can these judgments causally determine the content of her belief. And, as a result, the immediate causal impact account gets the scope of the prescriptive epistemic 'ought' wrong by implausibly restricting the set of beliefs over which we can exercise doxastic control. As such, the immediate causal impact account lacks the resources to vindicate the prescriptive character of significant portions of our evaluative practice in the epistemic domain. ${ }^{13}$

\section{Laying the Foundation for an Account of Doxastic Control}

Nevertheless, there is something right, I think, about the way that proponents of the immediate causal impact account have understood what the task of supplying an account of doxastic control involves. The immediate causal impact account is a natural way of developing an intuitively appealing and fundamentally correct line of thought regarding what an account of doxastic control will have to look like if it is to do the work that it is supposed to do in explaining why epistemic evaluation is appropriately prescriptive.

It is easy enough to imagine the proponent of the immediate causal impact account motivating her view in the following way. Notice that we think a believer is appropriately subject to prescriptive epistemic evaluation only if she can follow, respond

\footnotetext{
13 One could, of course, endorse the immediate causal impact account of doxastic control and simply accept that the scope of prescriptive epistemic evaluation is much more limited than our evaluative practice suggests. But I take it that, if possible, we ought to avoid this kind of error theoretic account of our evaluative practice. And the reminder of this paper aims to show that avoiding an error theory here is possible.
} 
to, or be guided by epistemic evaluations that she regards as having merit or as being apt. ${ }^{14}$ And this result raises the following question: how is it possible for the way in which a believer actually believes to be responsive to or guided by epistemic evaluation?

Here is the skeleton of an answer. Imagine that a believer accepts an epistemic evaluation as apt, perhaps by endorsing a normative judgment with the same content as the evaluation. ${ }^{15}$ If this judgment about how the believer ought to believe can shape the way in which she actually believes, then the evaluation can get a grip on the way in which the believer actually believes via her normative judgment. As a result, the believer can come to conform to the epistemic standards to which the evaluation gives voice.

The suggestion here is that if a believer takes an epistemic evaluation on board, perhaps by making the right sort of normative judgment, then, when all goes well, her having taken the evaluation on board will shape the way in which she actually believes going forward such that she ends up believing in the way in which the evaluation suggests she ought to believe. ${ }^{16,17}$ And, plausibly, this is just what it takes for it to be the case that a believer can respond to and be guided by epistemic evaluation in the way that makes such evaluation appropriately prescriptive in character.

If this answer to the "how is it possible..." question with which we began is at least roughly correct, then a believer can follow, respond to, or be guided by epistemic evaluations because the way in which she actually believes can be somehow regulated by or responsive to her understanding of how she ought to believe. So, if the fact that a

\footnotetext{
14 Although I will not pursue the thought here, I believe what follows is a natural way of cashing out the idea that the prescriptive 'ought' (in the domain of epistemology and elsewhere) implies some sort of 'can.'

15 Certain theorists - e.g. Sosa (forthcoming) and Shah (2003)-suggest that the relevant second-order state here is not a normative judgment regarding how one ought to believe, but rather an intention to regulate one's beliefs in a certain way (e.g. an intention to believe that $\mathrm{P}$ only if $\mathrm{P}$ is true). I ignore this wrinkle in my discussion because the success of the arguments both in defense of and against the different accounts of doxastic control that I canvas here do not turn on whether we understand the second-order state in question as being a normative judgment or an intention or some other sort of state.

16 This way of putting things might make it seem as if the right place to look for an explanation of the prescriptive character of epistemic evaluation is in the literature on rule-following in the epistemic domain. However I think, for reasons that are particularly clearly expressed in Boghossian (2008), that attempts to explicate our capacity to exercise doxastic control in terms of conventional accounts of our ability to follow epistemic rules will not yield fruit.

${ }^{17}$ I take it that the fact that the ways in which we actually believe are somehow coupled to how we think we ought to believe partially constitutes, or at the very least helps underwrite, our capacity to believe for, in response to, and on the basis of (what we take to be) reasons. And so, I agree, in the main, with those who have suggested that the capacity to exercise doxastic control is bound up with or best understood in terms of the capacity to believe for, in response to, or on the basis of what one takes to be reasons (e.g. McHugh (2012), (forthcoming) or Boyle (2011), (forthcoming)), or what I take to be the related capacity to settle for oneself the question of whether P in a way that makes one answerable (Hieronymi (2006), (2008), (2009)). However, I do not regard these views as competitors to the accounts of doxastic control that I canvas here. Rather, I take the accounts of doxastic control that I canvas here to provide different ways of spelling out part of what it takes to have the capacity to believe for, in response to, or on the basis of (what one takes to be) reasons, and/or part of that in virtue of which it makes sense to say that believing that $\mathrm{P}$ involves settling for oneself the question of whether P. I hope to explore the connection between the capacity for doxastic control and the capacity to respond to reasons in believing in more detail in later work.
} 
believer exercises doxastic control is to explain why a believer is appropriately subject to prescriptive epistemic evaluation, it follows that exercising doxastic control must involve being such that the way in which one actually forms, revises, or sustains one's beliefs is somehow the product of or regulated by one's own conception of ideal belief formation, maintenance, and revision. ${ }^{18}$ Put differently, a believer exercises doxastic control in believing when her understanding of how she ought to believe is coupled to the ways in which she actually believes such that she can come to believe in the ways that she thinks she ought to believe (at least in part) because she thinks that she ought to believe in those ways. A believer exercises doxastic control when, should she judge that she ought to believe in a certain way, her judgment is sufficient on its own to bring the way in which she believes closer in line with her conception of the relevant epistemic ideal. Exercising doxastic control involves having capacity to actually believe in the image of how one accepts that one ought to believe.

Of course, this first pass at describing what is involved in exercising doxastic control, however intuitively appealing, is too underdeveloped and uninformative to underwrite a satisfying explanation of when and why believers are appropriately subject to prescriptive epistemic evaluation for believing as they do. An explanatorily powerful account of doxastic control will have to describe the particular mechanism via which how a believer actually believes is responsive to or shaped by her conception of the relevant epistemic ideals. ${ }^{19}$ That is, an account of doxastic control will have to spell out the way in which a believer's judgments about how she ought to believe are coupled to the way in which she actually believes. And this is precisely what the immediate causal impact account purports to do.

18 I assume here that a believer's conception of ideal belief regulation is, at least in paradigmatic cases, constituted by her normative judgments about how she ought to believe, and can be given voice by her intentions to regulate her beliefs in certain specific ways.

19 Imagine a believer who believes that $\sim \mathrm{P}$ and that $\mathrm{PvQ}$, wonders whether $\mathrm{Q}$, and elects to undergo a procedure of targeted electromagnetic stimulation that will cause her to form a belief that $Q$ on the basis of her beliefs that $\sim \mathrm{P}$ and that $\mathrm{PvQ}$ because she judges that she ought to reason in this way in the circumstances at hand. This believer's normative judgment about how she ought to reason in the case at hand is causally efficacious with respect to the operation of the belief-regulating processes that actually generate and sustain her belief that Q. And perhaps this is enough to ensure that the believer is appropriately subject to some kind of prescriptive epistemic evaluation for believing as she does. In cases like this one, a believer exercises a kind of control that Hieronymi has helpfully identified as manipulative or managerial control in her (2006) or (2008) over how she believes. I do not mean to deny that we can and sometimes do exercise manipulative or managerial control over how we believe. I do think, however, that our evaluative practice presupposes that this is not the only, or even the primary, kind of control that we exercise in believing. And this is because when we employ the prescriptive epistemic 'ought' in criticizing one another, we often presuppose that we are capable of correcting our belief-regulating practices directly, so to speak, without having to manipulate our environment and as soon as we are made aware of the way in which we have fallen short of epistemic standards. In this sense, our evaluative practice presupposes that we are equipped with the capacity to exercise doxastic control in virtue of being wired up in the way that we are, not in virtue of the contingent features of the environment in which we operate. Thus, we should expect that an account of doxastic control will not be simply an account of our capacity to exercise manipulative control over how we believe. Rather, the mechanism via which our conception of ideal belief regulations is coupled to the way in which we actually regulate our beliefs will be tighter and more direct than this. 
There are, however, alternative strategies one might pursue in unpacking this coupling metaphor. An account of doxastic control that spells out the way in which a believer's normative judgments about how she ought to believe are coupled to how she actually believes in terms of causal efficacy might well endorse a story of the particular causal relationship between how one actually believes, on the one hand, and one's judgment about how one ought to believe, on the other, that differs substantially from the one that the immediate causal impact account puts forward. Or, one might spell out the link between a believer's normative judgments and her actual belief regulation by appeal to a metaphysical relation (e.g. constitution) instead of causal efficacy.

In what follows, I articulate a new kind of causal impact account, according to which our normative judgments can shape how we actually believe by influencing which belief-regulating dispositions we manifest when we believe, that succeeds where the immediate causal impact account fails in capturing the scope of the prescriptive epistemic 'ought'. Finally, I explain why we ought to favor this account - the disposition regulation account - over a metaphysical account of doxastic control.

\section{Coupling as Deferred Causal Impact: The Disposition Regulation Account of Doxastic Control}

Let us assume, for the moment, that some sort of causal impact account is right and so that it is some kind of causal link between a believer's judgments about how she ought to regulate her beliefs and how she actually regulates her beliefs that constitutes the mechanism of doxastic control. The immediate causal impact account was untenable because there is good reason to think that, at least in certain otherwise-ordinary casesour judgments about how we ought to believe in the particular set of circumstances with which we are currently faced cannot immediately and directly exert causal power on the ways in which we actually believe in those circumstances. Thus, I propose instead that our judgments about how we ought to believe can get a causal grip on how we actually believe by immediately and directly exerting their causal power in shaping the ways in which we are disposed to regulate our beliefs. In slogan form, I propose that our judgments regarding how we ought to believe shape what we might call our cognitive characters. And so, when the way in which we actually believe manifests our cognitive characters, our normative judgments shape how we actually believe. ${ }^{20}$

Typically, at least, the way in which one believes in any particular set of circumstances manifests one's belief-regulating dispositions. And, as I'll argue below, there is reason to think that, again, at least typically, a believer's judgments about how she

\footnotetext{
20 The disposition regulation account does not entail a virtue theoretic account of the structure of epistemic standards, and one certainly need not be a virtue epistemologist in order to endorse the disposition regulation account of doxastic control. If fact, none of the accounts of doxastic control that I canvas here take a stand on the structure or the content of epistemic standards or norms. However, the disposition regulation account does fit quite naturally with the virtue theoretic approach since it maintains that, in the first instance, we exercise doxastic control over our belief-regulating dispositions and so over our cognitive characters. As such, it offers a way of spelling out the mechanism that underwrites the kind of explicitly virtue-based account of epistemic responsibility that one finds, for example, in Owens (2000).
} 
ought to believe can be causally efficacious all on their own in shaping the way in which she is disposed to form, revise, and sustain her beliefs. ${ }^{21}$ Thus, I propose that a believer exercises doxastic control when her judgments about how she ought to believe in circumstances similar to those with which she is currently faced are causally efficacious in shaping the belief-regulating disposition(s) that she manifests in believing as she now does. So, a believer exercises doxastic control in believing that $\mathrm{P}$ if and only if she is wired up, so to speak, such that her judgments about how she ought to believe in circumstances like the ones with which she is now faced have this kind of direct causal impact on the strength of the various belief-regulating dispositions that she manifests in now believing that P. According to this account - the disposition regulation account - a believer is appropriately subject to prescriptive epistemic evaluation when, were she to make the relevant sort of normative judgment, her judgment would exert a kind of causal influence over the dispositions that she manifests in believing as she does via strengthening her disposition to regulate her beliefs in the way that she judges she ought to regulate her beliefs. If the disposition regulation account is roughly correct, then we exercise doxastic control in believing because (i) the ways in which we actually believe manifest our beliefregulating dispositions and (ii) a complete causal explanation of why it is that we are disposed to regulate our beliefs in certain ways and not others cites our understanding of the ways in which we ought to regulate our beliefs.

We can model the mechanism of disposition regulation by normative judgment as follows. ${ }^{22}$

${ }^{21}$ Of course, there are a slew of background conditions that must obtain if the normative judgment is to exert causal power in the way described. Perhaps the normative judgment will not be causally efficacious in shaping how the believer is disposed to form, revise, and sustain her beliefs if, just as the believer makes the normative judgment, she has a seizure, or sustains a serious brain injury, or if a mad scientist uses a small electrode to stimulate the believer's brain in a certain particular way, etc. Certainly the 'all on its own' language that I employ here and below is not meant to suggest otherwise. This language is only meant to mark that, unlike when Pascal's judgment that he ought to believe that God exists causes him to so believe (by first causing him take actions that he knows will result in his acquiring the belief in question), there is nothing that a believer must do, no further action that the believer must take, for her normative judgment to be causally efficacious in the way described.

22 This model is not the only way to model disposition regulation by normative judgment. What is essential to the disposition regulation account of doxastic control is just that a believer's normative judgment is immediately causally efficacious in shaping the believer's belief-regulating dispositions, but not in shaping the believer's current beliefs (although, as I explain below, the believer's normative judgment will have a kind of deferred causal impact on her beliefs by shaping the belief-regulating dispositions that give rise to those beliefs). It is not essential to the account that the normative judgment itself be caused in any particular way. 


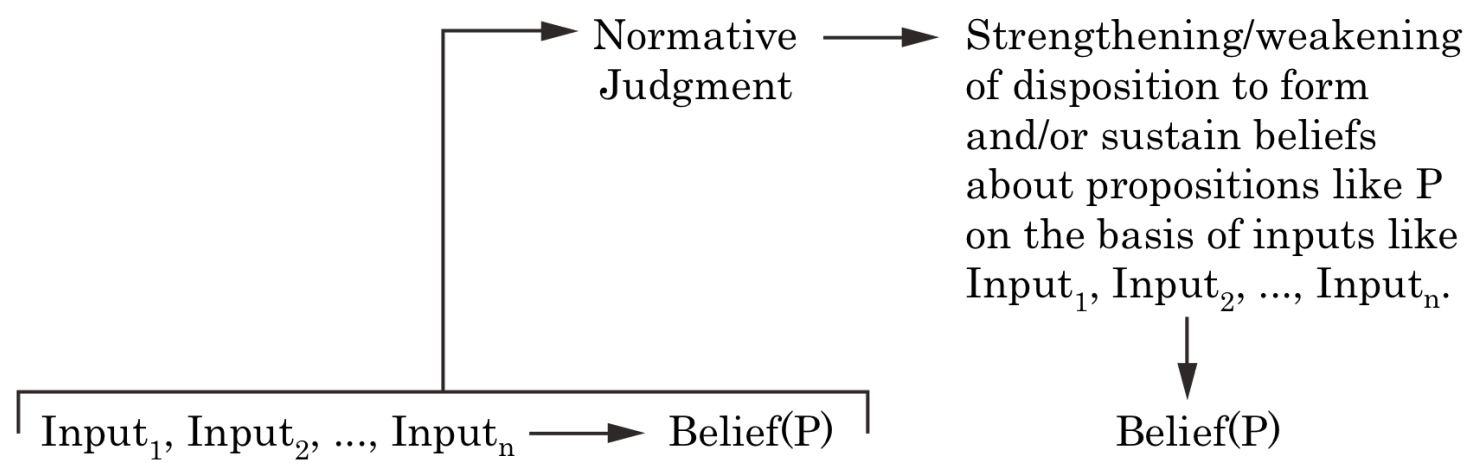

The bottom-most horizontal arrow in this diagram represents the way in which certain of the subject's particular perceptual experiences and other beliefs serve as the basis or grounds for belief about whether $\mathrm{P}$ in an actual or hypothetical case. Put in other terms, this arrow represents the cognitive processing that actually or hypothetically causes or sustains belief about whether $\mathrm{P}$ on the basis of Input ${ }_{1}, \ldots$, Input $\mathrm{t}_{\mathrm{n}}$ In reflecting on a particular cognitive transition or pattern of reasoning, a believer might judge it to be epistemically required, epistemically permissible, or epistemically forbidden. And should she so judge, this normative judgment will affect the strength of her corresponding beliefregulating disposition. So on the disposition regulation account, exercising doxastic control in believing that $\mathrm{P}$ involves it being the case that one's normative judgments about how one ought now to regulate one's beliefs in response to these inputs (i.e. perceptual experiences, other beliefs, etc.) shapes how one's cognitive system is disposed to translate

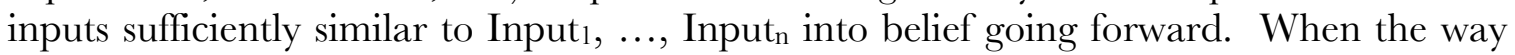
in which a believer believes manifests belief-regulating dispositions the strength of which can be influenced by the believer's normative judgments in the way described here, the believer exercises doxastic control in believing as she does.

If the disposition regulation account is right, then one can follow instructions or advice regarding how to regulate one's beliefs because one's judgments about how one ought to believe can be (in part) causally responsible for what one actually believes. As such, the kind of causal link to which the disposition regulation account appeals supplies us with a natural way of understanding what it takes for a believer to be responsive to or guided by her conception of ideal belief regulation in actually regulating her beliefs. ${ }^{23}$ On the disposition regulation account, however, one's judgments about how one ought to believe can be partially causally responsible for how one actually believes only by being partially causally responsible for the disposition to form, revise, and sustain one's beliefs in

${ }^{23}$ I suggested above (in note 17) that I think an account of the way in which a believer's conception of ideal belief regulation is coupled to her actual belief regulation ought to help illuminate what it takes to believe for, in response to, or on the basis of reasons. And, although I do not have space to develop the idea here, I think the disposition regulation account can also help us understand what is involved in believing in response to, for, or on the basis of reasons. Very roughly, perhaps believing for, in response to, or on the basis of reasons involves its being the case that the way in which one believes manifests a belief-regulating disposition the strength of which itself manifest the causal influence of the believer's understanding of how she ought to believe. 
certain ways that one manifests in believing. Thus, in contrast to the immediate causal impact account, the disposition regulation account is a deferred causal impact account. If the disposition regulation account is right, then the believer's normative judgment has no immediate causal impact on how she now believes. ${ }^{24}$ As a result, the disposition regulation account escapes the kind of criticism that I have argued undermines the immediate causal impact account.

Furthermore, the disposition account posits that the causal impact that a believer's normative judgments have on the strength of belief-regulating dispositions is entirely automatic and unreflective. This strengthening or weakening effect is not, for example, modulated by the believer's intentional efforts to bring her dispositions in line with her normative judgments. Thus, the disposition regulation account does not objectionably over-complicate the cognitive processes that generate, sustain, and revise belief, nor does it over-intellectualize the way in which we come to have the belief-regulating dispositions or cognitive habits that we have.

Finally, there is some empirical reason to think that we are actually wired up, so to speak, in the way that the disposition regulation account suggests. Early results in psychology on the effectiveness of if-then planning (i.e. planning via implementation intention) in shaping future behavioral, affective, and cognitive responses to stimuli constitutes some reason to expect that certain sorts of normative judgments can have precisely the kind of impact on our belief-regulating dispositions that the disposition regulation account proposes. ${ }^{25}$ These results suggest that if-then plans (e.g. if I find cookies in the mail room when I go to get a cup of coffee, then I will not eat them) are especially effective in shaping future behavioral, affective, and cognitive responses to stimuli because if-then plans forge an associative link between specific stimuli and a target response. Furthermore, researchers suggest that the effect the of this link (or perhaps part of what constitutes the associative link itself) is the automatic strengthening of a subject's disposition to respond to the set of stimuli catalogued in the antecedent of the plan in the way specified by the consequent. The more easily identifiable or recognizable and the less abstractly specified the relevant inputs and output are, the stronger the strengthening effect will be.

Crucially, judgments regarding how one ought to believe in response to various sorts of cognitive inputs are like implementation intentions in the following respect: normative judgments regarding how one ought to believe pair a set of inputs to cognitive processing with a target output. One might judge that, for example, if one's perceptual experience represents one's immediate surroundings as being thus-and-so and circumstances are otherwise normal (inputs), one ought to believe that one's immediate surroundings are thus-and-so (target output). Thus, the effectiveness of if-then planning in shaping a subject's dispositions to respond to stimuli in specific ways constitutes

\footnotetext{
${ }^{24}$ And, although I cannot pursue the idea here, it is for this reason that I believe the disposition regulation account is well positioned to underwrite an account of epistemic agency that is not vulnerable to the kinds of objections that Boyle (2011) raises against "process theories" of epistemic agency.

${ }^{25}$ For a quite comprehensive review of the relevant psychological literature, see Webb, T. L., Schweiger Gallo, I., Miles, E., Gollwitzer, P. M., \& Sheeran, P. (2012) or Gollwitzer, P. M., \& Sheeran, P. (2006).
} 
preliminary psychological evidence that a believer's normative judgments about how she ought to regulate her beliefs can directly and automatically shape her belief-regulating dispositions. ${ }^{26}$

\section{Coupling as Causal Impact vs. Coupling as Metaphysical Constitution}

The disposition regulation account and the immediate causal impact account both maintain that the right way to cash out the idea that our normative judgments about how we ought to believe are coupled to the way in which we actually believe is to describe a mechanism of causal influence that links our normative judgments to how we actually believe. One might think, however, that the sense in which our beliefs are coupled to our normative judgments regarding how we ought to believe is metaphysical rather than causal. Perhaps the way in which our normative judgments about how to believe are coupled to - and so, in some sense, can guide or shape - how we actually believe, is not best understood in terms of our normative judgments somehow exerting causal influence over either our belief-regulating processes or over the contents of our beliefs, but rather in terms of there being some sort of special metaphysical relationship that links our beliefs to our normative judgments about how to believe.

The constitution account of doxastic control is grounded in precisely this line of thought. According to the constitution account, judging that I ought now believe that $\mathrm{P}$ constitutively involves actually believing that $\mathrm{P}$. Believing that $\mathrm{P}$ is just part of what is involved in making a normative judgment that one ought to now believe that P. ${ }^{27}$ As a result, on the constitution account, it is metaphysically impossible for a believer to judge that she ought to believe that $\mathrm{P}$ in the circumstances at hand and yet fail to now believe that $\mathrm{P}$, because the latter mental attitude partially constitutes the former. ${ }^{28}$ Insofar as one

${ }^{26}$ Furthermore, this research suggests that the normative judgments that will have the most pronounced effects on a believer's belief-regulating dispositions will be normative judgments which link easily recognizable inputs with a specific target output (e.g. if sky is gray, the pavement is wet, and the trees are dripping and one's circumstances are otherwise normal, then one ought to believe that it has rained).

27 If one thinks, as I do, that there could be believers who lack the capacity to make normative judgments about their own mental attitudes, then one must deny the converse constitution claim (i.e. the claim that a belief that $\mathrm{P}$ is partially constituted by a normative judgment that one ought now to believe that $\mathrm{P}$ ). However, one might think that our capacity for belief (understood as an essentially rational capacity, and, at least in this regard, as being fundamentally different from any capacity that non-rational animals might have) and our capacity to make normative judgments about our own mental attitudes are metaphysically bound together. Put differently, one might think that our capacity to make normative judgments about how we ought to believe fundamentally alters the nature of our capacity to believe. And if something along these lines is right, then it is plausible that, at least for believers like us, both the original constitution claim and its converse hold: a normative judgment that one ought now to believe that $\mathrm{P}$ partially constitutes one's belief that $\mathrm{P}$ and vice versa. On this sort of view, believing that $\mathrm{P}$ on some particular basis and judging that one ought to believe that $\mathrm{P}$ on that very basis constitute a kind of metaphysical package: the belief partially constitutes the normative judgment and the normative judgment partially constitutes the belief. I think it is most charitable to read Boyle (forthcoming), (2011) and Korsgaard (2006) as endorsing just this kind of view.

28 An account of the metaphysical link that connects first-order beliefs and normative judgments about how we ought to believe according to which a normative judgment that one ought now to believe that $\mathrm{P}$ partially 
judges that one ought now believe that $\mathrm{P}$, it is metaphysically guaranteed that one also now believes that $\mathrm{P}$. And it is this fact, according to the constitution account, that underwrites one's capacity to follow or be guided by instructions or advice regarding how to reason that one accepts as apt. So, the fact that our beliefs are coupled to our normative judgments via constitution explains why we are appropriately subject to genuinely prescriptive epistemic evaluation.

We can model what, according to the constitution account, exercising doxastic control involves as follows.

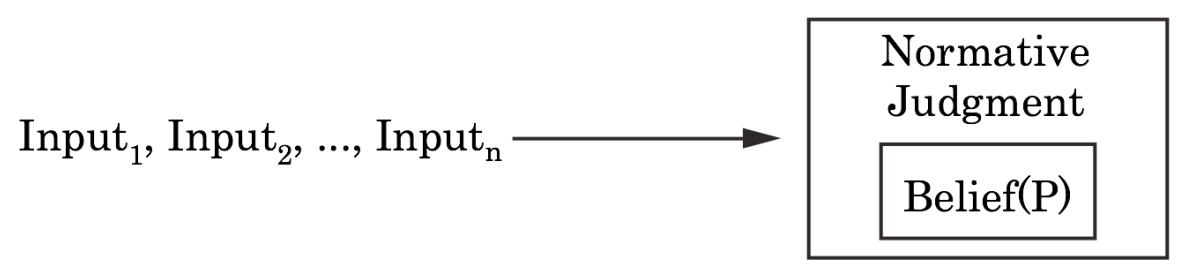

So, why favor a causal impact account - and, in particular, the disposition regulation account - over the constitution account? Let me be clear: I offer no argument here against the claim that a believer's belief that $\mathrm{P}$ partially constitutes her normative judgment that she ought now to believe that P. For all I say below, it may well be that our normative judgments about how we ought now to believe are partially constituted by our first-order beliefs in just the way that a proponent of the constitution account suggests. ${ }^{29}$ Nevertheless, I think we have good reason to reject the constitution account of doxastic control.

Here is why. Notice that we are appropriately subject to genuinely prescriptive praise or criticism in virtue not only of how we believe, but also how we intend, hope, fear, anger, etc. We think that one is reasonable, rational, or justified in intending, hoping, fearing, feeling pride, or feeling anger as a result of and in response to certain sorts of mental inputs, but not others. We think, for example, that one ought to intend to $\phi$ as a result of and in response to having certain combinations of beliefs and values or ends, but not as a result of and in response to having other combinations of beliefs and values or ends. And when we praise or criticize one another for intending, hoping, or

constitutes one's belief that P, but one's belief that $\mathrm{P}$ does not partially constitute one's normative judgment that one ought to now believe that $\mathrm{P}$ will not be able to explain why it is that we are capable of following the instructions, directions, or advice embedded in prescriptive epistemic evaluation. This is because we accept, internalize, or take up instructions or advice by making a normative judgment. And so a metaphysical connection between normative judgment and belief can only explain why we are capable of following or being guided by instructions or advice that we regard as apt if making a normative judgment metaphysically guarantees that we believe in accordance with the judgment that we make. The thesis that one's belief that P partially constitutes one's normative judgment that one ought now to believe that P can underwrite this metaphysical guarantee. The thesis that a normative judgment that one ought now to believe that $\mathrm{P}$ partially constitutes one's belief that $\mathrm{P}$, however, cannot.

${ }^{29}$ One might worry that the constitution account is obviously false since I can judge that I ought to believe that $\mathrm{P}$ because I am being offered a reward and yet fail to so believe. But this is too quick. The normative judgments to which the constitution account is meant to apply involve the epistemic 'ought,' and it is far less clear that one can judge that one epistemically ought to believe that $\mathrm{P}$ and yet fail to believe that $\mathrm{P}$. 
fearing in certain ways, our praise or criticism is often instructive or directive in character. Evaluations with respect to the various different standards of rationality, reasonableness, or justification that govern the ways in which we regulate the various different sorts of mental attitudes that we have can be and often are genuinely prescriptive.

This shows, I think, that there is a broader genus of prescriptive evaluation-I'll call it rational evaluation - of which prescriptive epistemic evaluation is a species. One is appropriately subject to prescriptive rational evaluation in virtue of having a particular mental attitude whenever that attitude is of a sort for which one can be appropriately asked to provide justifying or rationalizing reasons. And so, doxastic control (whatever it involves) must be a species of a more general type of control - I'll call it rational controlthat explains when and why individuals are appropriately subject to prescriptive evaluation with respect to the norms of rationality or justification that govern how we form, revise, and maintain the various different sorts of mental attitudes that we have. We ought to be able to generalize an account of doxastic control - an account of the link between a believer's normative judgments regarding how she ought to believe and how she actually believes - to generate an account of rational control that can explain when and why all sorts of rational evaluation are prescriptive. I argue below that we ought to favor the disposition regulation account of doxastic control over the constitution account of doxastic control because the former can be naturally extended to provide a unified account of rational control and the latter cannot. ${ }^{30}$

The reason that the constitution account of doxastic control cannot supply a unified account of rational control is that, even assuming it is plausible that one's normative judgment that one ought now to believe that $\mathrm{P}$ is constitutively linked to one's belief that $\mathrm{P}$, it is not at all plausible that one's normative judgment that one ought now to have a certain mental state (e.g. an intention to $\phi$, a wish or hope that $\mathrm{P}$, a fear of $\mathrm{X}$ ) is constitutively linked to the first-order mental state that one's normative judgment is about. Focus on the case of intention for a moment. If I judge that, given how desperately I want to stick to my diet, I ought to intend to refrain from eating the scoop ice cream that has been put in front of me, I may, nevertheless, find myself quite intentionally digging in. And I might well intend to have another serving of ice cream when I am through, while judging that I ought not so intend. Cases like these suggest that it is possible to make a normative judgment that one ought, in the circumstances at hand, intend to $\phi$, and yet fail to now intend to $\phi$, and that it is possible to intend to $\phi$

30 Either a reflective control account or a reflective guidance account of the mechanism of rational control might seem promising, at least at first pass, as applied to the cases of intention, hope, fear, etc. David Owens, for example, endorses a reflective control account of the kind of control we exercise in intending, although he denies that we have the capacity for reflective control over our beliefs. Perhaps he is right that our intentions are responsive to our normative judgments in just the way that a reflective control model suggests. Nevertheless, since neither reflective control nor reflective guidance provides a suitable model of doxastic control, to adopt either sort of account as an account of rational control amounts to rejecting that there is a unified account of rational control and so a unified explanation of when and why subjects are prescriptively evaluable in believing and in intending, hoping, fearing, etc. In light of the apparent unity in the phenomena to be explained, giving up on supplying a unified account here should be viewed as a kind of last resort, one that this section shows there is no need to pursue. 
without judging that one ought now intend to $\phi \cdot{ }^{31,32}$ But if the normative judgment that one ought now to intend to $\phi$ is not necessarily accompanied by the intention to $\phi$, then it cannot be that an intention to $\phi$ partially constitutes this judgment. And if one's intention to $\phi$ is not necessarily accompanied by the normative judgment that one ought now so intend, then this judgment cannot partially constitute the intention to $\phi$.

We cannot explain why agents are often appropriately subject to prescriptive rational evaluation in virtue of how they intend by understanding the link between an agent's normative judgments and her intentions in terms of constitution, because it is implausible that an agent's normative judgments and her intentions are actually metaphysically linked in this way. ${ }^{33}$ If we accept the constitution account of doxastic control, then we must also accept that there is no unified explanation of when and why we are subject to prescriptive rational evaluation for regulating the various different sorts of mental attitudes that we have in the ways that we do.

However, the disposition regulation account of doxastic control can be naturally extended to supply a unified account of rational control, and so to underwrite a unified explanation of the (sometimes) prescriptive character of rational evaluation of various different mental attitude types. Let us focus again on intention. Imagine I judge that I ought to intend to perform $\mathrm{M}$ when I adopt a particular end $\mathrm{E}$, and believe that performing a particular action $\mathrm{M}$ constitutes a necessary means to achieving $\mathrm{E}$. If I exercise rational control in intending, then according to the disposition regulation account of rational control, my normative judgment will be sufficient on its own to strengthen my disposition to intend to perform actions that I believe to be the necessary means to my various ends. Put in other terms, my normative judgment that I ought to form intentions in response to my beliefs and my ends in a way that corresponds to the pattern of reasoning described here itself strengthens my disposition to form intentions in precisely this way. And if I judge often enough that I ought to regulate my intentions in a

\footnotetext{
${ }^{31}$ It is perhaps natural to think that something like what I describe here is precisely what is going on in cases of practical akrasia, but I mean to remain agnostic regarding whether or not this is the right way of understanding that phenomenon. Regardless, what I describe here seems to be possible, and that is enough for the present argument.

32 Perhaps the proponent of a constitution account might respond as follows in an effort to rescue her view: in the first of these cases, I intend both to eat the ice cream and to refrain from eating the ice cream; in the second, I judge both that I ought and that I ought not to have another scoop. However, this way of interpreting what is going on in these cases is in conflict with the phenomenology of the agent. If asked in the second case whether I think that I ought to intend to have a second scoop of ice cream, I might respond by saying, "of course not! I know that I'll feel sick if I have another scoop! I'm standing in line for another scoop because I intend to have one even though I know that I ought not. I wish that I could give up my intention to have another scoop, but alas, I am overcome by temptation." At the very least, considerations of simplicity and parsimony tell against interpreting the cases in the way suggested here, and so, without independent motivation, this move is ad hoc at best.

33 It is even less plausible, I think, that one's normative judgments regarding what one ought to fear are constitutively linked to one's fears, or that one one's normative judgments regarding in virtue of what one ought to feel pride are constitutively linked to feeling proud.
} 
way that corresponds to this pattern of regulation, I will develop a strong standing disposition to regulate my intentions in just this way.

The psychological results that I discuss above lend support to the thesis that we are wired up, so to speak, just as the disposition regulation account suggests, just as much in the case of intention as in the case of belief. So it is plausible that my normative judgments are causally efficacious with respect to my intention-regulating dispositions in precisely this way. And, just as in the case of belief, the fact that they are is enough to ensure that I can, in the relevant sense, follow instructions or directives regarding how to form, revise, and sustain my intention. If I judge that I ought to intend to perform $\mathrm{M}$ when I adopt a particular end $\mathrm{E}$, and believe that performing a particular action $\mathrm{M}$ constitutes a necessary means to achieving E, then (assuming I have the capacity for rational control) just by making this judgment, I am on my way toward developing a standing disposition to form intentions in a way that conforms with my judgment about how I ought to intend. If an agent who exercises rational control over how she intends takes up the instructions embedded in a bit of rational praise or criticism by judging that she ought to regulate her intentions in the way that these instructions describe, the way in which she actually intends going forward will have been guided by these instructions. Thus, if the disposition regulation account is right, then the fact that an agent can exercise rational control in intending is enough to explain why she is appropriately subject to genuinely prescriptive evaluation for intending as she does.

As such, a disposition regulation account of rational control is well suited to explain when and why we appropriately take each other to be targets of genuinely prescriptive evaluation with respect to standards of rationality or justification in intending. And there is no reason to doubt that an analogous explanation of when and why we appropriately take each other to be targets of genuinely prescriptive rational evaluation in virtue of how we regulate various other sorts of mental attitudes that we have is in the offing. ${ }^{34}$ Thus, the disposition regulation account is especially well positioned to underwrite a unified account of when and why we are appropriate targets of prescriptive evaluation in virtue of how we form, revise, and sustain the range of different types of mental attitudes that we are capable of having. ${ }^{35}$

\footnotetext{
${ }^{34}$ Although I do not have space here for a detailed discussion of this point, I think it is quite plausible that we enjoy different degrees of rational control over our different types of mental attitudes. Perhaps, for example, we are more capable of exercising rational control in believing and intending than in fearing, wishing, or angering. If this is right, then we have yet another reason to favor a disposition regulation account over a constitution account of rational control: the kind of strengthening effect to which a disposition regulation account appeals might well take on different magnitudes in cases involving different mental attitude types, but constitution cannot come in degrees.

35 Although a full treatment of the issue is beyond the scope of this paper, I believe that a disposition regulation account of rational control can also supply a satisfying explanation of when and why individuals, as well as group agents (a board of directors, a government agency, etc.), are subject to genuinely prescriptive evaluation with respect to standards of rationality or justification in virtue of how they act. Notice that this is precisely what we should expect if, as I suggest above in notes 17 and 23, an account of this sort of control helps to explain what it takes to be reasons-responsive, since both individuals and group agents are typically responsive to reasons in acting.
} 


\section{Conclusion}

Here is an intuitively appealing thought about what is required for a believer to have the capacity to be guided by instructions regarding how to believe: a believer is capable of responding to instructions or directions regarding how she ought to believe because the way in which she actually forms, revises, and maintains her beliefs is somehow coupled to and can be regulated by her own conception of how she ought to form, revise, and maintain her beliefs. Plausibly, then, it is this link between a believer's conception of ideal belief regulation and her actual belief regulation that constitutes her capacity to exercise doxastic control. The mechanism of doxastic control is just the mechanism via which a believer's conception of ideal belief regulation is coupled to the ways in which she actually regulates her beliefs.

The immediate causal impact account, the disposition regulation account, and the constitution account are all inspired by and best understood as attempts to flesh out this foundational thought. I argue, however, that the disposition regulation account is better positioned than its competitors to supply a satisfying explanation of when and why it is that believers are appropriately subject to prescriptive epistemic evaluation for believing as they do. The immediate causal impact account rightly cashes out the link between a believer's normative judgments regarding how she ought to believe and the way in which she actually believes in terms of a kind of causal impact that the former have on the latter. But the immediate causal impact account is committed to an implausibly immediate model of this causal connection. Thus, the disposition regulation account, according to which a believer's normative judgments regarding how she ought to believe have a kind of deferred causal impact on how she actually believes, succeeds where the immediate causal impact account fails in explaining the scope of prescriptive epistemic evaluation. Furthermore, the disposition regulation account can underwrite a plausible and unified explanation of when and why evaluation with respect to the different standards of rationality, justification, or reasonableness that govern our various different types of mental attitudes is prescriptive, while the constitution account cannot. ${ }^{36}$

${ }^{36}$ I am especially grateful to Matthew Kotzen, Lisa Miracchi, Ram Neta, Blake Roeber, Geoffrey SayreMcCord, Nishiten Shah, Susanna Siegel, Ernest Sosa, Kurt Sylvan, and Vida Yao for their feedback on earlier drafts of this piece. 


\section{References}

Boghossian, Paul (2008). "Epistemic rules." Fournal of Philosophy 105 (9):472-500.

Boyle, Matthew (forthcoming). "Active Belief." Canadian Fournal of Philosophy 41.

- (2011). “'Making up Your Mind' and the Activity of Reason." Philosophers' Imprint 11 (17).

Chrisman, Matthew (2012). "'Ought' and Control." Australasian Fournal of Philosophy 90 (3):433-451.

— (2008). “Ought to Believe.” Journal of Philosophy 105 (7):346-370.

Gollwitzer, P. M., \& Sheeran, P. (2006). "Implementation Intentions and Goal

Achievement: A Meta-Analysis of Effects and Processes." Advances in Experimental Social Psychology, 38, 69-119.

Hieronymi, Pamela (2009). "Two Kinds of Agency.” In Lucy O'Brien \& Matthew

Soteriou (eds.), Mental Action. Oxford University Press.

— (2008). "Responsibility for Believing." Synthese 161, 357-373.

— (2006). "Controlling Attitudes." Pacific Philosophical Quarterly 87 (1):45-74.

Kornblith, Hilary (2002). Knowledge and its Place in Nature. Oxford University Press.

Korsgaard, Christine M. (2008). The Constitution of Agency: Essays on Practical Reason and

Moral Psychology. Oxford: Oxford University Press.

- (1996). The Sources of Normativity. Cambridge University Press.

McDowell, John. (1994). Mind and World. Cambridge: Harvard University Press.

McHugh, Conor. (forthcoming). "Exercising Doxastic Freedom." Philosophy and Phenomenological Research.

— (2012). "Control of Belief and Intention." Thought 1 (4):337-346.

Owens, David (2000). Reason Without Freedom: The Problem of Epistemic Normativity. New York: Routledge.

Scanlon, Thomas M. (1998). What We Owe to Each Other. Cambridge: Belknap Press of Harvard University Press.

Shah, Nishi (ms). "Why We Reason the Way We Do"

— (2003). "How Truth Governs Belief." Philosophical Review 112, 447-482.

Shah, Nishi \& Velleman, J. David (2005). "Doxastic Deliberation.” Philosophical Review 114 (4), 497-534. 
Sosa, Ernest (forthcoming). "Epistemic Agency." The fournal of Philosophy.

- (2009). A Virtue Epistemology: Apt Belief and Reflective Knowledge, Volume I.

Oxford: Oxford University Press.

Webb, T. L., Schweiger Gallo, I., Miles, E., Gollwitzer, P. M., \& Sheeran, P.

(2012). "Effective regulation of affect: An action control perspective on emotion regulation." European Review of Social Psychology, 23, 143-186. 